\title{
COMMUNITY STRUCTURE ANALYSIS OF ENDOPARASITIC HELMINTHS OF ANABAS TESTUDINEUS (BLOCH, 1792) FROM A FRESH WATER BODY OF BANGLADESH
}

\author{
AMINUL ISLAM BHUIYAN ${ }^{1}$, MD OSMAN GHANI AND JANNATUL BUSHRA \\ Department of Zoology, University of Dhaka, Dhaka 1000, Bangladesh
}

\begin{abstract}
Community structure of the parasites of Anabas testudineus was analyzed collected from a fresh water body, Turag River at Diabari, Mirpur point of Dhaka, Bangladesh. Out of $50 \mathrm{~A}$. testudineus fish observed, $36(72 \%)$ were parasitized by at least one species of helminth endoparasites. Six metazoan endoparasites were recorded: two trematodes (Allocreadium minutum, Neopecoelina saharanpuriensis) and four nematodes (Ascaridida sp., Gnathostoma spinigerum, Contracaecum sp., Paragendria wallagonia). Prevalence was higher in female (81.25\%) hosts than male $(55.56 \%)$. Nematode was more prevalent group $(70 \%)$ than trematode $(62 \%)$. All parasite species were accounted as secondary species category; no central or satellite species accounted in the sample. A significant positive correlation was observed between the standard length of the host with the prevalence and abundance of all parasites in this sample fishes. Two parasites (A. minutum and Ascaridida sp.) showed typical over-dispersed distribution pattern and other four parasites ( $N$. saharanpuriensis, $G$. spinigerum, Contracaecum sp. and $P$. wallagonia) showed random distribution pattern. Interspecies association between two species of parasite was moderately strong. The host's sex did not affect the parasite diversity and abundance.
\end{abstract}

Key words: Endoparasite, Anabas, Community structure, Component community, Infra community

\section{Introduction}

Rivers are characterized as ecosystems subjected to constant water supply that leads to adaptations in their organisms, resulting in the presence of communities with characteristic structure and functions (Junk et al. 1989). Parasitic diseases, either alone or in conjunction with other environmental stresses may influence weight or reproduction of the host, alter its population characteristics, which may affect its economic importance (Rhode 1993). Parasites occupy a definite position in the animal kingdom for their remarkable adaptations and damaging activities to host. Every parasite living in or on a fish, extents some degree of harmful influence on its host thus normal growth of fishes is interrupted or inhibited if they are heavily infected with parasites. Environmental modifications can alter the population dynamics of the ichthyofauna, as well as their physiological and biological conditions which influencing the structure and composition of the parasitic fauna. There are also physicochemical factors of water such as dissolved oxygen, pollution, temperature, turbulence etc. can contribute to the emergence of new one and increase parasite species richness (Pavanelli et al. 1997). Factors that determine

1 Corresponding author: Email: aminul islam89@yahoo.com 
the composition and structure of natural communities have always been at the core of ecology (Ricklef and Schluter 1993). Parasites can shape its community structure through their effects in trophic interactions, food webs, competition, and biodiversity around them.

Investigation on parasite community structure in aquatic environment are scarce and seldom in Bangladesh. Ghani and Bhuiyan (2011) worked on comparative community structure of endoparasitic helminths of Channa punctatus from a non-polluted river and a polluted sewage lagoon of Bangladesh. Thus the aims of the study was to extend the knowledge about the endoparasitic fauna of Anabas testudineus, through determining its parasite diversity at component and infra- community structure level, and to analyze the possible influence of host sex and standard length and others from a fresh water body of Bangladesh.

\section{Materials and Methods}

The present study was conducted by investigation of parasites of host fish Anabas testudineus collected from Beribadh area of Turag River at Diabari, Mirpur, Dhaka, Bangladesh $\left(23^{\circ} 52^{\prime} \mathrm{N}-90^{\circ} 24^{\prime} \mathrm{E}\right)$ during April-October, 2012. One attempt was made each month to collect fish but we could collect fish during months of April ( $\mathrm{n}=12)$, May $(\mathrm{n}=10)$, September $(\mathrm{n}=7)$ and October $(\mathrm{n}=21)$. Fish were not available during rest of the months. Fifty $A$. testudineus individuals were collected from local fishermen during the study period. Sample fishes were collected from its habitat water as live and immediately brought to the parasitology laboratory of the Department of Zoology, University of Dhaka for investigation. The river body's average width and depth are $400 \mathrm{~m}$ and $10 \mathrm{~m}$ respectively.

Investigation on helminth parasites: The examination was aimed to determine endoparasitic helminths infection of $A$. testudineus. Length, sex and organ wise infections of fish by each parasite species were recorded. Length and sex of hosts were noted before autopsy. Extensive search was made for helminth parasites infecting the fish using Leica Zoom 2000 Dissecting Microscopes. All parasites from each organ were sorted, cleaned, counted and then were preserved in $70 \%$ alcohol. The trematodes were stained in acetic carmine for 2-3 hours depending on size of specimens. After staining, the worms were washed in $70 \%$ alcohol to which a few drops of glacial acetic acid were added. Then they were cleaned and temporarily mounted in lactophenol. Nematodes were cleaned and temporarily mounted in lactophenol for microscope study. Berland method (1982) was used for staining and mounting. Species identification was done by using taxonomic keys from Yamaguti $(1958,1961)$. Two nematodes, Ascaridida and Contracaecum could not be identified to species level, therefore referred as Ascaridida sp. and Contracaecum sp.

Calculation and data analysis: To describe the structure of the infra- and componentcommunities, data was related to parasite abundance, prevalence and intensity were 
calculated according to Bush et al. (1997). The methods used here to describe general features of parasite infra-communities (prevalence, abundance, and intensity) and component community. Component community structure of parasite was described in two ways: traditional descriptors (e.g. species richness, mean abundance and mean intensity) and community similarity. Measurement of dominance, species richness and evenness also followed standard definitions given by Begon et al. (1996).

Status of distribution: The classification of the species was done according to the importance value for the community as Central species $=$ present in more than $66.6 \%$; Secondary species $=$ present between $33.3 \%$ to $66.6 \%$ and Satellite species $=$ lower than $33.3 \%$ of the total number of fish analyzed (Bush and Holmes 1986).

Dispersion indices: Two criteria namely Green's dispersion index (GI) (Green 1966) and index of dispersion $(D I)$ were used to evaluate the dispersion pattern of parasite species. Dispersion index was tested using statistical ' $d$ ' as most of the parasite species did not follow theoretical Poisson distribution series. Distribution of parasites was classified as aggregated when $d>1.96$; regular when $d<-1.96$ and random when $d<1.96$ (Ludwig and Reynolds 1988).

Diversity indices: Simpson (1949) diversity index $(\lambda)$ was determined for the sample and for infinite population Simpson unbiased estimator () and Shannon's (Shannon and Weaver $1949)$ index of diversity $\left(H^{\prime}\right)$ were used.

Evenness and equitability: Three indices as Heip (1974) evenness index $\left(E_{h}\right)$, Hill (1973) evenness index $\left(E_{H}\right)$ and Modified Hill's ratio $\left(E_{H}^{\prime}\right)$ were used to determine species evenness.

Correlation: Pearson linear correlation coefficient $(r)$ and Spearman's rank correlation coefficient $\left(r_{s}\right)$ were computed to determine possible correlations between the host's standard length with the prevalence and abundance of each parasite species respectively (Zar 1996).

Existence of association: Jaccard index detects the existence of association between species for measuring the degree of association. It always contains a value between 0 to 1 and as the value approaches to 1 , indicates the association between species is high.

For determining the probable variation of infection in relation to host sex with abundance of parasite species, Mann-Whitney 'U' test was conducted.

The analysis included only component parasite species i.e. whose prevalence was greater than 10\% (Bush et al. 1990). Community structure of parasites has been determined as a function of host habitats, sizes, sexes. Statistical tests were conducted by using XLSTAT 2011 (Kruskal-Wallis test) and SPSS 16.0 (Pearson linear correlation, Spearman's rank correlation and Mann-Whitney ' $U$ ' test) software package. The statistical significance level adopted was $p \leq 0.05$. 


\section{Results and Discussion}

Component community structure: Altogether six helminth endoparasites were recorded during the present study. Among them, two were digeneans identified as Allocreadium minutum, Neopecoelina saharanpuriensis and four were nematodes as Ascaridida sp., Gnathostoma spinigerum, Contracaecum sp. and Paragendria wallagonia. Some $72 \%$ fishes was parasitized by one or more species of helminth endoparasites. Investigation on infestation with different groups of parasites shows that infestation with trematode (62\%) was lower than that with nematode (70\%) endohelminths (Fig. 1). Akther et al. (2001) worked on histopathology of nematode infection and reported seven species of nematodes from $A$. testudineus collected from Dhaka city markets. Parveen et al. (2006) recorded seven helminths: three trematodes (Neopecoelina saharapurensis, Ptychogonimus megastomus, Brevicreadium) and four nematodes (Metaquimperia madhuai, Zeylanema anabantia, Z. bidigitalis, Gnathostoma spinigerum ) from A. testudineus of Bangladesh. Of the four nematodes found of the present study only Gnathostoma spinigerum and of two trematodes only Neopecoelina saharanpuriensis were common with those of Parveen et al. (2006). They found $90 \%$ fish infected by at least one helminth parasite.

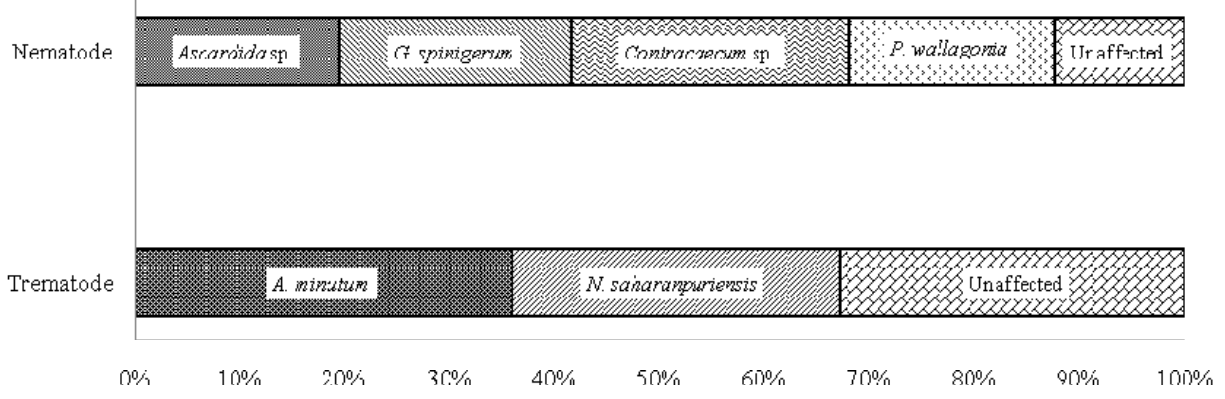

Fig. 1. Infestation of A. testudineus with different groups of parasite.

The prevalence of trematode group was lower than nematode group because trematodes have a very complex life cycle, and transmitted by means of interactions between preypredator and presence or absence of snail community as an intermediate host for completing life cycle of these parasites (Marcogliese and Cone 1996). In the host body, the most preferred habitat for these parasites was intestine. However, three nematodes (Ascaridida sp., G. spinigerum, Contracaecum sp.) were also found in both intestine and stomach. Out of six parasites, two digenean (A. minutum, $N$. saharanpuriensis) and one nematode ( $P$. wallagonia) species were found at their adult stage. Other three nematodes (Ascaridida sp., G. spinigerum, Contracaecum sp.) were at their larval stages (Table 1). A. minutum was relatively the most dominant species (23.64\% of all parasites) followed by Ascaridida sp. (19.77\%). 
Community structure analysis of endoparasitic

Table 1. Location of infection, developmental stage and dominance of parasites collected from $A$. testudineus.

\begin{tabular}{lcccccc}
\hline Name of parasites & $\begin{array}{c}\text { Location } \\
\text { of } \\
\text { infection }\end{array}$ & $\begin{array}{c}\text { Developmental } \\
\text { stage }\end{array}$ & $\begin{array}{c}\text { No. of } \\
\text { infected } \\
\text { fish }\end{array}$ & $\begin{array}{c}\text { No. of } \\
\text { parasite }\end{array}$ & Ranges & $\begin{array}{c}\text { Relative } \\
\text { dominance }\end{array}$ \\
\hline A. minutum & I & Adult & 26 & 61 & $1-4$ & $23.64 \%$ \\
N. saharanpuriensis & I & Adult & 20 & 34 & $1-3$ & $13.18 \%$ \\
Ascardida sp. & S,I & Larva & 22 & 51 & $1-5$ & $19.77 \%$ \\
G. spinigerum & S,I & Larva & 21 & 38 & $1-2$ & $14.73 \%$ \\
Contracaecum sp. & S,I & Larva & 23 & 46 & $1-3$ & $17.83 \%$ \\
P. wallagonia & I & Adult & 14 & 28 & $1-2$ & $10.85 \%$ \\
\hline
\end{tabular}

I=Intestine; $\mathrm{S}=$ Stomach

The occurrence of more parasites in the intestine than in the stomach might be due to the presence of digested food present there or due to greater surface area presented by the intestine (Adebanjo 1979). Smith (1981) reported that most parasites inhabit the intestine because of their general feeding habits. Larvae might actually survive by being encapsulated in a tough sheath inside the body cavity of the fish, and high prevalence in birds could be attributed to easy access to prey in the river (Barson 2004).

With the importance value based on prevalence only, Contracaecum sp. was considered the dominant species $(60 \%)$. According to status of distribution, all parasite species were considered as secondary species; no central or satellite species was accounted. In the sample, parasite species with higher mean intensity and abundance of $A$. minutum was $2.65 \pm 1.19$ and $1.22 \pm 1.56$, respectively (Table 2).

Table 2. Prevalence (P\%), mean intensity (MI), mean abundance (MA) with standard deviation (SD) and status of the species of the helminth endoparasite community of $A$. testudineus.

\begin{tabular}{lcccc}
\hline Name of the parasites & $\mathrm{P}(\%)$ & $\mathrm{MI} \pm \mathrm{SD}$ & $\mathrm{MA} \pm \mathrm{SD}$ & Status \\
\hline A. minutum & 46 & $1.22 \pm 1.56$ & $2.65 \pm 1.19$ & Secondary \\
N. saharanpuriensis & 40 & $0.68 \pm 0.98$ & $1.70 \pm 0.73$ & Secondary \\
Ascaridida sp. & 44 & $1.02 \pm 1.50$ & $2.32 \pm 1.46$ & Secondary \\
G. spinigerum & 50 & $0.76 \pm 0.85$ & $1.52 \pm 0.51$ & Secondary \\
Contracaecum sp. & 60 & $0.92 \pm 0.99$ & $1.53 \pm 0.82$ & Secondary \\
P. wallagonia & 44 & $0.56 \pm 0.70$ & $1.27 \pm 0.46$ & Secondary \\
\hline
\end{tabular}

The high prevalence of Contracaecum sp. mjght be due to the fact that the intermediate host (usually copepode) being the main diet of $A$. testudineus. Esch et al. (1990) reported that the parasite community with its prevalence and intensity might be influenced by the age and length of the host, changes in the diet, in the volume of food ingested, ontogenetic changes in the immuno-competence and changes in probability of contact with intermediate hosts. 
Infracommunity structure: Parasites of $A$. testudineus had shown typical over dispersed type of distribution pattern (Table 3). Ascaridida sp. showed the highest dispersion index value $(D I=2.206)$ suggesting their highest clumping distribution $(d=4.854)$ in the fish and the d-value for A. minutum ( $\mathrm{d}>1.96$ ) also suggested aggregated pattern of distribution in host body; other species showed their random distribution. We also found negative value of ' $d$ ' for $G$. spinigerum and $P$. wallagonia indicating its distribution trends to regular pattern (but $d$ is not less than -1.96).

Table 3: Values of variance to mean ratio of parasite abundance $(D I)$ and Green's aggregate index $(G I)$ and statistical ' $d$ ' value of the metazoan parasites of $A$. testudineus.

\begin{tabular}{lcccc}
\hline Name of parasites & DI & GI & d & Distribution type \\
\hline A. minutum & 1.984 & 0.016 & 4.095 & Aggregated \\
N. saharanpuriensis & 1.412 & 0.012 & 1.914 & Random \\
Ascaridida sp. & 2.206 & 0.004 & 4.854 & Aggregated \\
G. spinigerum & 0.951 & -0.001 & -0.195 & Random \\
Contracaecum sp. & 1.065 & 0.001 & 0.367 & Random \\
P. wallagonia & 0.875 & -0.005 & -0.589 & Random \\
\hline
\end{tabular}

Aggregated distribution of the parasite populations is considered as one of the most common features of metazoan parasite infections (Poulin 1993). In the present study, two aggregation measures were used: the variance-to-mean ratio $(D I)$ and Green's dispersion index $(G I)$. Values obtained from these two indices revealed a low aggregation level of distribution of the constituent parasite species. According to Anderson and Gordon (1982), this pattern of aggregate dispersion may have originated- (a) from the heterogeneity of the host's behavior; (b) by patterns of spatial aggregation in the distribution of infective stages; and (c) by the differences of susceptibility and capacity of the hosts' immunological reaction.

Species richness of the sample was 6. Lower value of Simpson's index $(\lambda=0.178)$, Simpson's unbiased estimator $(=0.174)$ and higher value of Shannon's index $\left(H^{\prime}=1.758\right)$ indicated that diversification of parasite community was well developed. Evenness of parasite distribution was also counted with Heip evenness index $\left(E_{h}=0.960\right)$ and Hill's evenness index $\left(E_{H}=0.968\right)$ which showed moderately higher value meant that community structure was well constructed by evenly distribution of all parasite species (Table 4). 
Table 4. Diversity and evenness measures of helminth endoparasite communities of $A$. testudineus.

\begin{tabular}{lc}
\hline Diversity/Evenness indices & Values in the sample \\
\hline Simpson index $(\lambda)$ & 0.178 \\
Simpson unbiased estimator () & 0.174 \\
Shannon index $\left(H^{\prime}\right)$ & 1.758 \\
Heip evenness index $\left(E_{h}\right)$ & 0.960 \\
Hill's evenness index $\left(E_{H}\right)$ & 0.968 \\
Modified Hill's ratio $\left(E_{H}^{\prime}\right)$ & 0.962 \\
\hline
\end{tabular}

According to Sasal et al. (1999), the diet of the host species is the main factor affecting parasite community structure, especially for digenean trematodes that are transmitted to their final host through a predator-prey relationship. These authors proposed that hosts with a more diversified diet should encounter more intermediate host species and, consequently harbor more parasite species. Guégan et al. (1992) postulated that- (a) the diversity of endohelminths varies between sites or between species of hosts and; (b) the diversity of helminths is related to the size of the host, longevity and diet. They also claimed that size and diet together explain approximately $40 \%$ of the variance in the diversity of endohelminths of hosts. Therefore, it may be suggested that feeding habit existed in A. testudineus was one of the most relevant factors for explaining the difference of endoparasitic diversity and richness of the fish community; that is $A$. testudineus occupy higher diverse feeding qualities, present them favourable conditions to endoparasitic infection because they include a greater number of prey species in their diet. In the sample, Evenness index obtained was high and probably it was related to the lower value of Simpson index, indicating that no endoparasites species presented such a high intensity of infection that could influence the size of the other endoparasitic infrapopulations.

Infection in relation to host's standard length: According to Pearson's correlation coefficient and Spearman's rank correlation coefficients, significant positive correlation was observed between the host standard length and the prevalence and abundance for all parasite species in this sample specimens at $\mathrm{p}<0.05$ or $\mathrm{p}<0.01$ level of significance(Table 5).

Table 5. Pearson's correlation coefficients $(r)$ and Spearman's rank correlation coefficients $\left(r_{s}\right)$ to evaluate the relationship between abundance and prevalence with standard length of $A$. testudineus.

\begin{tabular}{lcccc}
\hline Name of parasites & $\mathrm{r}$ & $\mathrm{p}$ & $\mathrm{r}_{\mathrm{s}}$ & $\mathrm{p}$ \\
\hline A. minutum & 0.491 & $0.000^{* *}$ & 0.525 & $0.000^{* *}$ \\
N. saharanpuriensis & 0.044 & $0.001^{* *}$ & 0.465 & $0.001^{* *}$ \\
Ascaridida sp. & 0.537 & $0.000^{* *}$ & 0.631 & $0.000^{* *}$ \\
G. spinigerum & 0.489 & $0.000^{* *}$ & 0.563 & $0.000^{* *}$ \\
Contracaecum sp. & 0.370 & $0.008^{* *}$ & 0.349 & $0.013^{*}$ \\
P. wallagonia & 0.393 & $0.005^{* *}$ & 0.406 & $0.003^{* *}$ \\
\hline
\end{tabular}

* Significance level $\mathrm{p}<0.05, * *$ Significance level $\mathrm{p}<0.01$ 
In the present study, host size was always positively correlated with the prevalence and abundance of the parasite species. The presence of relationship between abundance and prevalence with the host's standard length might be due to the presence of relationship between endoparasitic diversity and the body length of the host sample under analysis indicated that fish's growth rate might help in the process of equal recruitment of different parasite species in their habitat. This fact indicates homogeneity in their increase in body length during their life cycle and thus permits the uniform recruitment of the species of endoparasites throughout their life. As pointed out by Poulin (2000), these patterns cannot be generalized because in many host-parasite species systems the correlations are positive but weak and insignificant. Also ontogenetical changes in feeding behavior might influence parasite prevalence and abundance in the different host size classes (Saad-Fares and Combes 1992).

Infection in relation to host's sex: In the sample (50 fishes), 32 were female and 18 were male of which $26(81.25 \%)$ female and $10(55.75 \%)$ male fishes were infected with at least one parasite. According to the Mann-Whitney ' $\mathrm{Z}(\mathrm{U})$ ' test it was found that intensity of infection and parasite abundance was not significantly $(\mathrm{p}>0.05)$ related to the host's sex (Table 6).

Table 6. Values of Mann-Whitney test, Z(U) to evaluate the role of host sex and parasite abundance and prevalence in the sample.

\begin{tabular}{lcc}
\hline Name of parasites & $\mathrm{Z}(\mathrm{U})$ & $\mathrm{p}$ \\
\hline A. minutum & -0.789 & 0.425 \\
N. saharanpuriensis & -0.931 & 0.353 \\
Ascaridida sp. & -1.465 & 0.143 \\
G. spinigerum & -1.667 & 0.095 \\
Contracaecum $\mathrm{sp}$. & 1.152 & 0.249 \\
P. wallagonia & 0.222 & 0.824 \\
\hline
\end{tabular}

p: significant value.

The insignificant values with regard to host sex from Mann-Whitney test evidenced that the ecological relationships (occupation of habitat and diet) are similar among males and females. Same results have been obtained for other species of freshwater fishes (Janovy and Hardin 1988). Moreover, Poulin (1996) stated that high testosterone levels can cause immune-suppression in males and could lead in some cases to males suffering more from parasites than do females, although many parasite surveys have reported no significant differences in infection abundance and prevalence between female and male hosts.

In order to determine how often two or more species were found in same fish individual, Jaccard index $(J I)$ was used to observe the interspecific association between each pair of parasite species. From the value of JI, it can be considered that interspecific association of parasite was strong enough. The positive association between species pairs, as observed indicates that the species coexist in the same host without competition with 
respect to ecological requirements, probably because they do not occupy the same niche along the digestive tract (Table 7).

Table 7. Values of Jaccard's index (JI) to estimate interspecific association between each pair of parasite species of $A$. testudineus.

\begin{tabular}{l|cccccc}
\hline Name of parasites & (T1) & (T2) & (N1) & (N2) & (N3) & (N4) \\
\hline A. minutum (T1) & - & 0.483 & 0.665 & 0.517 & 0.519 & 0.452 \\
N. saharanpuriensis (T2) & 0.483 & - & 0.556 & 0.452 & 0.515 & 0.500 \\
Ascaridida sp. (N1) & 0.665 & 0.556 & - & 0.516 & 0.486 & 0.571 \\
G. spinigerum (N2) & 0.517 & 0.452 & 0.516 & - & 0.618 & 0.516 \\
Contracaecum sp. (N3) & 0.519 & 0.515 & 0.486 & 0.618 & - & 0.529 \\
P. wallagonia (N4) & 0.452 & 0.500 & 0.571 & 0.516 & 0.529 & - \\
\hline
\end{tabular}

Affinity present at the study for coexistence of two species is referred to as interspecific association. In general, an association between two species exists because: (a) both species select or avoid the same habitat or habitat factors; (b) they have the same general abiotic and biotic environmental requirements; or (c) one or both of the species has an affinity for the other, either attraction or repulsion (Hubalek 1982). From the results obtained from Jaccard index, it may be observed that there is no or less evidence of competition among the species of endoparasites in the host sample since for most cases species to species association occurred with higher values suggesting that they have the common and continuous reservoirs/intermediate hosts which remain stable with time. However, these data from quantitative associations between parasite species could be used with caution to explain the parasite community structure. According to Poulin (2001), interspecific relationships can only be considered valid when tested under experimental conditions. These results reinforce the postulate of Rohde et al. (1995) according to which the parasite community structure in marine fishes constitutes a confused and unsaturated species complex, unlike the interactive patterns related for other host groups.

It was not possible to discuss results of present finding with any fresh water fish of our region since no work has so far done except Ghani and Bhuiyan (2011) on community structure of any fresh water fish. However, it could be concluded from the observation that female fishes were more prevalently infected than males. Host's lengths were positively correlated with prevalence and abundance of parasites. Most of the parasites showed random distribution pattern while other showed typical over - dispersed distribution pattern.

\section{References}

Adebanjo, A.O. 1979. A survey of parasites of Clarias lazera in Dundaye area of Rima River, Sokoto, Project submitted to Zoology Unit of Biological Science, Usman Danfodio University, Sokoto, October, 1977 (ADM NA2052). 32pp. 
Akther, M., A. Khatum and J. D'Silva, 2001. Histopathology of climbing perch, Anabas testudineus Bloch (Perchiformes: Anabantidae) associated with tissue penetrating nematodes. Bangladesh J. Zool. 29(2): 107 - 117.

Anderson, R.M. and D.M. Gordon. 1982. Processes influencing the distribution of parasite numbers within host populations with special emphasis on parasite-induced host mortalities. Parasitology. 85: 373-398.

Barson, M. 2004. The occurrence of Contracaecum sp. larvae (Nematoda: Anisakidae) in the catfish Clarias gariepinus (Burchell) from Lake Chivero, Zimbabwe. Onderstepoort Journal of Veterinary Research. 71: 35-39.

Begon, M., J.L. Harper and C.R. Townsend. 1996. Ecology ( ${ }^{\text {th }}$ Edt.). Blackwell Science, Oxford, UK. pp. 469-498

Berland, B. 1982. Basic techniques involved in helminth preservation. In proceeding of workshop on"Technology as applied to museum parasite collections." ICOPA V- 1982. Toronto, Canada. pp 1-15.

Bush, A.O., J.C. Holmes. 1986. Intestinal helminths of lesser scaup ducks: An interactive community. Can. J. Zool. 64: 142-152.

Bush, A.O., J.M. Aho and C.R. Kennedy. 1990. Ecological versus phylogenetic determinants of helminth parasite community richness. Evolutionary Ecology. 4: 1-20.

Bush, A.O., K.D. Lafferty, J.M. Lotz and A.W. Shostak. 1997. Parasitology meets ecology on its own terms: Margolis et al. revisited. J. Parasitol. 83(4): 575-583.

Esch, G.W., A.W. Shostak, D.J. Marcogliese and T.M. Goater. 1990. Patterns, and processes in helminth parasite communities: an overview. In ESCH, GW., BUSH, AO. and AHO, J. (Eds.). Parasite communities: patterns and processes. New York: Chapman and Hall. pp. $1-19$.

Ghani, M.O. and A.I. Bhuiyan. 2011. Community structures of endoparasitic helminths of Channa punctatus from a fresh water river and a polluted lagoon of Bangladesh. Bangladesh J. Zool. 39(2): 173-185.

Green, R.H. 1966. Measurement of non-randomness in spatial distributions. Researches Population Ecology.8:1-7.

Guégan, J.F., A. Lambert, C. Lévêque, C. Combes, L. Euzet. 1992. Can host body size explain the parasite species richness in tropical freshwater fishes? Oecologia. 90: 197- 204.

Heip, C. 1974. A new index measuring evenness. J. of Mar. Biol. Association. 54: 555-557.

Hill, M.O. 1973. Diversity and evenness: a unifying notation and its consequences. Ecology. 54: 427-32.

Hubálek, Z. 1982. Coefficients of association and similarity, based on binary (presence-absence) data: an evaluation. Biological Reviews of the Cambridge Philosophical Society. 57(4): 669-689.

Janovy, J. and E.L. Hardin. 1988. Diversity of the parasite assemblage of Fundulus zebrinus in the Platte River of Nebraska. J. Parasitol. 74: 207-213.

Junk, W.J., P.B. Bayley, R.E. Sparks. 1989. The flood pulse concept in river floodplain systems. Can. Spec. Publ. Fish. Aquat. Sci. 106: 110-127.

Ludwig, J.A. and J.F. Reynolds. 1988. Statistical ecology: a primer on methods and computing. New York: Wiley-Interscience Publications, pp. 337.

Marcogliese, D.J. and D.K. Cone. 1996. On the distribution and abundance of eel parasites in Nova Scotia: influence of $\mathrm{p}^{\mathrm{H}}$. J. Parasitol. 82: 389-399.

Parveen, R., D'Silva, J., Khanum, H. and Zaman, Z. 2006. Helminth parasites in Anabas testudineus (Bloch, 1792). Bangladesh J. Zool. 34(1): 35 - 40. 
Pavanelli, G.C. M.H. Machado and R.M. Takemoto. 1997. Fauna helmíntica de peixes do rio Paraná, região de Porto Rico, PR. In: A. E. A. M. Vazzoler, A. A. Agostinho, N. S. Hahn (eds.), A planície de inundação do alto rio Paraná: aspectos físicos, biológicos e socioeconômicos. Maringá, EDUEM, pp. 301-323.

Poulin, R. 1993. The disparity between observed and uniform distributions: a new look at parasite aggregation. Int. J. Parasitol. 23(7): 937-944.

Poulin, R. 1996. Helminth growth in vertebrate hosts: does host sex matter? Int. J. Parasitol. 26: 1311-1315.

Poulin, R. 2000. Variation in the intraspecific relationship between fish length and intensity of parasitic infection: biological and statistical causes. J. Fish. Biol. 56(1): 123-137.

Poulin, R. 2001. Interactions between species and the structure of helminth communities. Parasitology. 122: S3-S11.

Ricklefs, R.E. and D. Schluter. 1993. Species diversity in ecological communities: historical and geolographical perspectives. University of Chicago Press, Chicago, Illinois, USA. pp. 635-636

Rohde, K. 1993. Ecology of Marine Parasites, An Introduction to Marine Parasitology. $2^{\text {nd }}$ Edition. CAB International.

Rohde, K., C. Hayward and M. Heap. 1995. Aspects of the ecology of metazoan ectoparasites of marine fishes. International Journal for Parasitology. 25: 945-970.

Saad-Fares, A. and C. Combes. 1992. Abundance/host size relationships in a fish trematode community. J. Helminthol. 66(1): 87-192.

Sasal, P., N. Niquil and P. Bartoli. 1999. Community structure of digenean parasites of sparid and labrid fishes of the Mediterranean Sea: a new approach. Parasitol. 119: 635-648.

Shannon, C.E. and W. Weaver. 1949. The Mathematical Theory of Communication. University Illinois Press, Urbana. 338 pp.

Simpson, E.H. 1949. Measurement of diversity. Nature.163: 688-688.

Smith, A.C. 1981. Introduction of parasitology. Willey NewYork. 822 pp.

Yamaguti, S.1958. Systema helminthum. I. The trematodes of vertebrates. New York: Interscience, $575 \mathrm{pp}$

Yamaguti, S. 1961. Systema helminthum. III. The nematodes of vertebrates. Interscience, Publishers Inc., New York 261pp.

Zar, J.H. 1996. Biostatistical Analysis, 3rd ed., Prentice Hall, Inc., Upper Saddle River, New Jersey, $662 \mathrm{pp}$. 